\title{
Cartografía de y desde la crítica.
}

\section{Miradas contemporáneas (im)posibles para el Trabajo Social en Latinoamérica}

Cartography for and from Criticism. Contemporary (im)possible perspectives for Social Work in Latin America

Rodrigo Cortés Mancilla

Trabajador Social

(Universidad de Valparaíso)

Magíster en Políticas Sociales y Gestión Local

(Universidad de Arte y Ciencias Sociales)

Doctor en Trabajo Social

(Universidad Nacional de Rosario)

Académico-Investigador de la Escuela de

Trabajo Social, Facultad de Educación y

Ciencias Sociales

(Universidad Andrés Bello)

Coordinador Núcleo de Investigación

e Intervención Social con Territorios y

Comunidades de la Región de Valparaíso

Co-investigador Núcleo de investigación e incidencia Pública en Derechos Humanos de Valparaíso

Correo: rocortesman@gmail.com 


\section{Resumen}

El presente trabajo es producto de una reflexión acerca de la crítica contemporánea y cómo desde la cartografía se puede configurar una práctica discursiva espacial y situada en el Trabajo Social Latinoamericano. Para ello, se distinguen diferentes planteamientos críticos que se pueden articular no jerárquica, sino táctica y estratégicamente, frente a la discusión sobre y desde una praxis atravesada por la polémica, la contradicción y el desacuerdo. El mapa que se presenta, en cuanto prácticas discursivas, busca introducir a posiciones e implicancias teóricoprácticas de la crítica y sus posibilidades en Latinoamérica, conexiones o alianzas necesarias para robustecer un proyecto político superador de fronteras territoriales y disciplinares.

Palabras clave

Cartografía, Crítica, Trabajo Social, Deconstrucción.

\section{Abstract}

This paper is the result of a reflection on contemporary critique and how a spatial and situated discursive practice in Latin American Social Work can be configured from cartography. For this purpose, different critical approaches are distinguished, which can be articulated not hierarchically, but tactically and strategically, facing the discussion on and from a praxis crossed by polemic, contradiction and disagreement. The map presented, as discursive practices, seeks to introduce positions and theoretical-practical implications of criticism and its possibilities in Latin America, connections or alliances necessary to strengthen a political project overcoming territorial and disciplinary boundaries.

Keywords

Cartography, Criticism, Social Work, Deconstruction. 


\section{Introducción}

El artículo tiene como objetivo cartografiar deconstructivamente parte de la crítica contemporánea desde las Ciencias Sociales, y particularmente desde Trabajo Social, proponiendo posibilidades de revisión y articulación de perspectivas.

Así se pone en cuestión inicial el concepto de la crítica, lo crítico, perspectiva crítica, pensamiento crítico, que pone en tensión y contradicción, pero entrega certezas del compromiso más o menos explícito con relación a un proyecto de alianzas, preconiza rectificaciones de mayor o menor envergadura de lo existente.

La noción crítico y crítica, ha quedado oscurecida y desgastada por el uso desde lo actual, pero pensar contemporáneamente es reflexionar sobre esa historia de oscurecimiento y desgaste a partir de los sentidos originales, redireccionando la mirada al pasado para robustecer el presente y lo porvenir. Crítica que deviene de Krisis, Kritike, como crítico deviene de Kritikós, surge desde la idea de discernir la verdad evidenciando, previamente, la negación de ella.

Reconocemos un mapa histórico, político y científico complejo de la crítica, con diversas representaciones o significaciones, con una inevitable vulgarización y popularización, con usos cotidianos, pero que se extiende a distintos ámbitos, como en lo académico. ¿Qué pensamos de la crítica en las ciencias sociales en general y el Trabajo Social en particular? ¿Hay posibilidades de renovar el pensamiento crítico? Pero eso implica reconocer los sentidos y significados desde perspectivas, que involucra luchar y generar alianzas, entre visiones y disciplinas asociadas tanto al concepto de crítica desde las y los maestros, como de quienes devienen como herederos y herederas de ellas y ellos.

Este artículo propone una ruta cartográfica para deconstruir la crítica y proyectar posibilidades para las ciencias y el Trabajo Social latinoamericano.

\section{Trazos cartográficos}

El camino construido en el artículo deviene de una cartografía (Bambó-Naya et al., 2019; Deleuze y Guattari, 2020; Pérez de Lama, 2009; Rey y Granese, 2019) que es el mapa trazado conceptualmente 
como una red en cuestión: intuitivo en muchas de sus líneas, articulada a través de una multiplicidad conectiva, cambiante, significante. No se trata de reinstalar dicotomías o binarismos, como construcción de sentidos e identidades (de género, de clase, étnicas o políticas), la red permite aproximarse a las intersecciones, quizá tendrá sus zonas de repetición, de redundancias, de trans-fronteras y tensiones. El concepto de cartografía, como método, tiene sus raíces en Mil Mesetas (Deleuze y Guattari, 2020) como una de las particularidades del rizoma.

Para estos autores, el rizoma procede por variación, expansión, conquista, captura e inyección. Contrariamente al grafismo, al dibujo o a la fotografía, contrariamente a los calcos, el rizoma está relacionado con un mapa que debe ser producido, construido, siempre desmontable, conectable, alterable, modificable, con múltiples entradas y salidas, con sus líneas de fuga.

Con lo anterior, quien cartografía se envuelve en las fuerzas del territorio o del dispositivo y las sigue. ¿Qué líneas seguir, hasta dónde continuarlas, cuándo se cortan? Estas son las preguntas para hacerse dentro de una articulación y en la construcción de una cartografía, más que representar un mundo que esté ya dado, sospecha la identificación de nuevos elementos, la creación de nuevas relaciones. Este mapa no puede ser independiente del sujeto que lo traza.

Es importante relevar que la disposición cartográfica se instala como un método de comprensión e interpretación en diferentes ramas de las ciencias sociales.

La tarea del cartógrafo deseante no consiste en captar para fijar, para anquilosar, para congelar aquello que explora, sino que se dispone a intensificar los propios flujos de vida en los que se envuelve, creando territorio a medida que se los recorre (Perlongher, 1996:65).

La propuesta claramente sobrepasa una representación gráfica de la crítica, facilitaría el entendimiento espacial de los objetos, sería una particular y situada representación de la realidad que selecciona qué es lo que debe ser representado y qué no para constituir la imagen eficaz de lo real. 
Se propone desconfiar de la representación, producto de una lógica binaria para explicar el mundo. El mapa no representa nada, no vuelve a presentar algo que preexiste, por el contrario, tiene un carácter articulador que cobra presencia a medida que se produce, de acuerdo con el devenir de los acontecimientos (Badiou, 2013; Žižek, 2018; Cortés, 2017), poniendo en marcha nuevas relaciones e interpretaciones.

Con lo anterior se da lugar a un devenir común, un nuevo acontecimiento de lo real, nuevas posibilidades por venir.

Ello no implica desconocer las relaciones de poder que atraviesan la cartografía y que ésta pone a funcionar como tecnología de producción de lo real y como herramienta de conocimiento, sino que esas relaciones son inmanentes a las múltiples líneas y elementos que componen al mapa, sean éstas sociales, políticas, mentales, acontecimentales, imaginarias, etc.

Esta cartografía pretende ser una revisión aguda y política en el campo situado, desde una praxis que ha implicado reflexividad y auto reflexión.

2. Deconstrucción de las líneas de campo y/o territorios de la crítica

La deconstrucción (Derrida, 1978, 2012; Derrida et al., 2014; Derrida y Roudinesco, 2009; Cortés, 2017, 2018) nos expone a leer entre las líneas del mapa, en los márgenes del texto y a través del discurso, para descubrir silencios y contradicciones que desafían la aparente honestidad de la categoría, de la noción: crítica.

Primero es comprender cuáles son y de dónde surgen las nociones y hasta qué punto han funcionado, históricamente, como una herramienta de discursos; deconstruir, además, nos permite las luchas por el signo: crítica, las alteraciones y las alianzas que permiten demarcar esas pugnas o relaciones de poder.

Creo que se comparte que la noción o concepto: crítica; trata de algo que la mayoría entendemos en un sentido común u ordinario, lo más probable que se comprende desde el significado que una hegemonía le ha otorgado. El asunto, no obstante, se complica si intentamos distinguir entre una crítica que es significada desde tal o cual posición 
y la crítica como una práctica discursiva más frecuente que pudiera ser descrita sin referencia a sus objetos concretos.

Entonces podemos preguntarnos: ¿Cuál es su carácter general sin insinuar una esencia de la crítica? Y si para establecer esta imagen general lo hiciéramos expresando algo que se aproximase a una praxis crítica.

Un cuidado y reconocimiento indispensable corresponde a la referencia teórica-práctica e ideológica de los clásicos (los maestros), es decir que toda posición crítica y radical se argumenta desde ese lugar que es el hilo conductor que nos moviliza desde Hegel y Marx hasta Freud y Nietzsche, que nos ilumina(n) en la interpretación crítica inherente de la sociedad capitalista. Es un legado tremendo, pero que implica en la práctica crítica actual ser herederos o herederas de ellos. Esto implica una interpretación contemporánea desde sus referencias, con base en ese potente legado, es así como la herencia deviene entonces deconstrucción, práctica de lectura perdurable, siempre dispuesta a hacer expandir el texto legado en múltiples y diversos sentidos, de acuerdo con el referenciado a la intencionalidad interpretativa.

El planteamiento sobre la herencia no promueve un culto al recuerdo, señalando que todo tiempo pretérito fue mejor. Lo que está en juego tiene relación con cómo abordamos lo que se nos lega; respondemos al llamado que se nos hace de recibir y reaccionar, sin que ello implique replicarlo a perpetuidad:

Si la herencia nos asigna tareas contradictorias (recibir y sin embargo escoger, acoger lo que viene antes que nosotros y sin embargo reinterpretarlo, etc.), es porque da fe de nuestra finitud. Únicamente un ser finito hereda, y su finitud lo obliga. Lo obliga a recibir lo que es más grande y más viejo y más poderoso y más duradero que él. Pero la misma finitud obliga a escoger, a preferir, a sacrificar, a excluir, a dejar caer. Justamente para responder al llamado que lo precedió, para responderle y para responder de él, tanto en su nombre como en el del otro. El concepto de responsabilidad no tiene el menor sentido fuera de una experiencia de la herencia (Derrida y Roudinesco, 2009:13). 
La herencia nos configura hacia la idea de la posición desde un pensamiento crítico contemporáneo, entendiendo lo contemporáneo (Cortés, 2018), para asumir que tiene una articulación con el pasado. Pero tenemos que aclarar que no siempre hay una seguridad o consistencia entre esas virtudes del pasado, que impliquen automáticamente méritos en el presente (no tendríamos los gobiernos que tenemos hoy, por ejemplo, en Chile).

Nuestros/as clásicos/as, los/as fundadores/as... son los espectros... no reemplazables... sí interpretables, por lo tanto son invariablemente contemporáneos.

Para Marx, como heredero era fundamental reconocer que:

El defecto fundamental de todo el materialismo anterior, es que solo concibe las cosas, la realidad, la sensoriedad, bajo la forma de objeto o de contemplación, pero no como actividad sensorial humana, no como práctica, no de un modo subjetivo. De aquí que el lado activo fuese desarrollado por el idealismo, por oposición al materialismo (...) Feuerbach quiere objetos sensoriales, realmente distintos de los objetos conceptuales; pero tampoco él concibe la propia actividad humana como una actividad objetiva. Por eso, en la esencia del cristianismo solo considera la actitud teórica como la auténticamente humana, mientras que concibe y fija la práctica solo en su forma suciamente judaica de manifestarse. Por tanto, no comprende la importancia de la actuación revolucionaria, 'práctico-crítica' (Marx y Engels, 1950:13-15).

Esa práctica crítica, revolucionaria, configura ese poder material en Marx:

Es cierto que el arma de la crítica no puede sustituir a la crítica de las armas, que el poder material tiene que derrocarse por medio del poder material, pero también la teoría se convierte en poder material tan pronto como se apodera de las masas (Marx, 2014:151).

Implica que toda perspectiva crítica no tiene poder para transformar la realidad por sí sola. El conocimiento no es directamente un 
arma, sino una posibilidad o potencial herramienta para transformar la realidad.

Así, posteriormente, Rosa Luxemburgo (2017) da cuenta de la transformación, iluminándonos como heredera en cómo se configura la crítica, construcción que además hace ante sus críticos en la interpretación de Marx:

A primera vista, puede parecer un ejercicio puramente teórico. Y, sin embargo, el significado práctico del problema está a la mano: la conexión con el hecho más notorio de nuestros tiempos: el imperialismo. Los típicos fenómenos externos del imperialismo: competencia entre países capitalistas para conquistar colonias y esferas de interés, oportunidades de inversión, sistema internacional de préstamos, militarismo, barreras arancelarias, papel dominante del capital de las finanzas y los monopolios en la política mundial, son todos ellos bien conocidos (...) ¿Cómo podemos explicar el imperialismo en una sociedad donde ya no hay espacio para él? Fue en este punto donde pensé que tenía que comenzar mi crítica (Luxemburgo, citado en Dunayevskaya, 2017:111).

La crítica en sí-para sí es siempre la praxis de alguna práctica-teórica, discurso, episteme o institución instituidos, y pierde su carácter en el momento en que se abstrae de esta forma de operar y se la aísla como una práctica puramente generalizable. Pero, aun siendo esto cierto, no significa que sea imposible algún tipo de generalización o que tengamos que salpicar en particularismos.

En 1978, Foucault pronunció una conferencia titulada ¿Qué es la crítica?, que encaminó su ensayo conocido como ¿Qué es la Ilustración?, capítulo del texto sobre la ilustración (Foucault, 2007). En él, no solamente se cuestiona lo que la crítica es, sino que también busca comprender qué tipo de cuestionamiento instituye la crítica, ofreciendo de forma tentativa algunas maneras de circunscribir su actividad. Lo que continúa siendo quizás lo más importante, es la estrategia interrogativa en que se formula el asunto. “¿Qué es la crítica?” forma parte del proyecto crítico en cuestión, así que la pregunta no plantea el dilema, lo que interpela es a pensar ¿cuál es la praxis crítica que se pretende? ¿Cuál es la praxis crítica que hacemos o que aspiramos? 
La crítica será dependiente de sus objetos, pero sus objetos a cambio precisarán y tensionarán el propio significado de la crítica. Más aún, la tarea primordial de la crítica no implicaría analizar binariamente si sus objetos - condiciones materiales, sociales, prácticas, formas de saber, poder y discurso- son buenos o malos, ensalzables o desestimables, sino en discusión el propio marco de revisión o evaluación.

La crítica "es instrumento, medio de un porvenir o de una verdad que ella misma no sabrá y no será, es una mirada sobre un dominio que se quiere fiscalizar y cuya ley no es capaz de establecer" (Foucault, 2007:34), como producto que se hace inteligible en la complejidad de las problemáticas que se han ido analizando por las ciencias sociales en general y el Trabajo Social particularmente en la investigación e intervención social.

La complejidad, categoría, junto con lo epistemológico, trabajada profunda y acertadamente por Alicia González-Saibene (2007, 2015, 2021), indudablemente nos permite comprender múltiples variedades internas en el pensamiento crítico. Por ello, las perspectivas críticas son plurales, dispares, caleidoscópicas. Cada una nombra conceptos, categorías, discursos, estructuras y subjetividades.

Es desde esa apuesta que el singular aísla el o los comunes denominadores diseminados que implican las ruinas heterogéneas. La heterogeneidad constituye una posición útil contra los usos dogmáticos que imaginan la crítica admitida como el prototipo de toda crítica posible, esa rigidez dogmática que el mismo Lenin develó.

Ante lo anterior se postula desde el desacuerdo (Rancière, 1994) como un tipo de situación de habla que no se genera por el conflicto entre antagónicos argumentativos dispersos, sino, precisamente, entre aquellos que se refieren a lo mismo, pero a eso mismo lo entienden de manera diferente. No opera como desconocimiento o ignorancia del otro que constituye el mismo espacio polémico, sino que se despliega ahí donde los argumentos se comprenden en tanto se constituyen recíprocamente sobre una referencia común.

Ante esa complejidad caleidoscópica, por ende heterogénea también, de la crítica, que encontramos mapeando socio-políticamente el territorio latinoamericano, situadas y articuladas desde los maestros, sin lugar a duda, desde ciertas visiones del mundo, a determinadas 
doctrinas a propósito de las historias, de las precariedades, de las manifestaciones de la cuestión social-colonial, con los diferendos ideológicos y políticos. Creo que ninguna opción se resume a un feudo profesional.

A continuación, propongo dos miradas o perspectivas de posibilidad: la Posibilidad de la Crítica desde la dialéctica sujeto individual y social y la Posibilidad de la crítica desde la deconstrucción del Lenguaje y el Deseo.

3. Posibilidad de la crítica desde la dialéctica sujeto individual y social

Desde la complejidad y posicionamiento situado en Latinoamérica, implica un proceso dialógico, colectivo, contradictorio, con pugnas y alianzas indispensables. En ese trabajo territorial realizado con compañeras y compañeros del núcleo de investigación e intervención social con territorios, con líderes y lideresas de colectivos, se generó una articulación no jerárquica que ha permitido articular una de las prácticas desde el intercambio de gramáticas en la complejidad (Cortés, 2020); con la intención de dar cuenta la posibilidad de situar una acción puntual (re)producida material y simbólicamente por esas prácticas .

Una práctica situada permite esa aproximación a las creencias, saberes, relaciones de poder y prácticas, en un espacio social construido desde ese vínculo sujeto individual y necesariamente social.

Esta posibilidad se ha transformado en una aproximación para interpretar nuestras respectivas posiciones sociales, intereses, sentimientos, deseos y preocupaciones que están materializados en signos, al igual que los enunciados que produzcan y comprendan en una formación económica-social y un proceso de producción (Karsz, 2007).

Es una mirada crítica del objetivismo abstracto, lo que implica aplicar el materialismo dialéctico a los estudios lingüísticos. El método obliga a ver el lenguaje dentro de un proceso creativo, social y en cambio permanente.

Se trata de ver la complejidad e integridad del problema, implica mirar los procesos -además de los objetos-, entender cómo llegaron a 
ser como son; el carácter ideológico o encubridor se extiende de este modo a las estructuras del sistema. Así "el sistema capitalista se produce y reproduce constantemente en lo económico a niveles cada vez más altos, así también la estructura cosificadora penetra en el curso de su desarrollo cada vez más profundamente, fatal y constitutivamente, en la conciencia” (Lukács, 2009:132-133). Pero frente a ese carácter permite aproximarnos a esas contradicciones internas y dilucidar cómo en el proceso se van resolviendo colectivamente y cómo se resolverán . Ejemplo de ello son las "tomas de terrenos", "el movimiento mapuche", "las ollas comunes", etc.

Se trata de comprender la historia social de los signos, como la historia de las ideologías. Es obvia la influencia de Marx y Engels, quienes en El Manifiesto Comunista (1848/2015) ya habían planteado las contradicciones dentro de los modos de producción como motor de los cambios históricos, mostrando que los cambios mantenían inalterables las principales leyes: la lucha de clases y la crisis de crecimiento de las fuerzas productivas.

Pero, contemporáneamente, revisito a Valentín Voloshinov (1999, 2009) quien propone desde ese método asumir las contradicciones que el lenguaje tiene: las lenguas tienen una historia, están siempre dadas dentro de una comunidad, pero están cambiando; la lengua de una comunidad es única, pero dentro de esa lengua se lucha por la imposición de valores, el significado no garantiza el sentido de lo enunciado, el contexto, el momento histórico de la enunciación -junto con otros elementos para verbales también contribuyen al sentido; la comprensión es el principio de la producción de otro enunciado como respuesta; los signos lingüísticos son utilizados en la comunicación inter individual pero también en el pensamiento individual, etcétera.

\subsection{Miradas a los signos e ideologías}

Comento la posibilidad de una aproximación a estudios del lenguaje abordando y compartiendo las interacciones cotidianas como foco de interés y unidad. Es aquí donde veremos la tarea de creación ideológica, la potencia del lenguaje. 
Esta propuesta surge desde el trabajo con pobladores y pobladoras que han planteado resignificar y deconstruir sus historias, por ejemplo, no permitir que les digan vecinos, si no poblador o pobladora, no el de ciudadanía, sino el de pueblo. Dan cuenta de que los signos no se presentan nunca aislados; los signos se presentan dentro de enunciados que son la unidad de sentido de la interacción lingüística.

Es ese imperativo de lo situado, en el sentido de que un enunciado es único e irrepetible, como tal es una creación única ligada a las condiciones concretas, sociales e históricas de producción.

Así, para producir un enunciado un hablante cualquiera no necesita de ningún tipo de aporte del exterior, ya que los signos, palabras, formas gramaticales, etcétera, ya están en la conciencia; cuando se emite un enunciado no puede emitirse otra cosa que lo que ya está de algún modo en ese conocimiento.

Contrario a De Saussure, Voloshinov habla de formación social, está pensando en una sociedad concreta e históricamente construida, en un modo de producción, con sus contradicciones de clase, su organización jerárquica, ideologías organizadas como la religión, la organización del derecho, etcétera (por ello, importa comprender la expansión del conservadurismo religioso en las poblaciones).

Por lo tanto, cuando habla de interacción lingüística no está pensando en una simple relación hablante-oyente, sino en una compleja red de relaciones sociales, con roles o posiciones predeterminados y con una ideología dominante. Y es ahí en donde propone el otro campo de lucha, donde puede existir revolución.

En caso de no entenderlo de este modo, nos costaría mucho explicar el sentido de la afirmación que el signo es una de las arenas de la lucha de clases o -aún más elemental- que el signo solo puede ocurrir en el terreno trans-subjetivo o interindividual, territorio que no es "natural", en los cuerpos, en las intervenciones, en las orgánicas... en el sentido directo de esa palabra: el signo tampoco puede surgir entre dos personas. Es necesario que ambos individuos estén socialmente organizados, que representen un colectivo: solo entonces puede surgir entre ellos un medio sígnico (semiótico).

Es indispensable, como plantea Saül Karsz (2007), explicitar que todos los signos son ideológicos y que no hay ideología sin signos, 
afirmando también que lo ideológico constituye un todo. Así reconocemos esa tríada hegeliana del en sí, para sí y el en sí-para sí), que no podemos analizar en la investigación o en la intervención un signo aislado. Es por ello que hacer una historia de la vida social de los signos será hacer una historia de las configuraciones ideológicas.

Para ejemplificar situadamente, en Chile se ha elegido una convención constitucional para escribir una nueva Constitución, donde se plantea un proceso democrático como signo que estará en pugna, ya que podría ser el oxímoron dentro de un horizonte ideológico del conservadurismo pensado como signo burgués. Proceso democrático que estará en pugna, tensionado, donde se articularán antagonismos y alianzas, como requisito de una práctica ideológica en nuestra formación económico social concreta, por lo tanto, cada signo debe ser y será una lucha revolucionaria. La ideología dominante intenta mono acentuar el signo, imponerle un único sentido posible, lo contra hegemónico, ese colectivo históricamente subalterno, pugnará por establecer su estrategia, sus tácticas para apropiarse del proceso, qué se cuenta de la revuelta popular de 2019 .

Entendemos a la ideología dominante, desde Althusser (1998), como la que llega a ser dominante por la actividad de lo que denomina los Aparatos Ideológicos de Estado, instituciones públicas o privadas especializadas en difundirla; trabajan por medio de la persuasión, utilizando el lenguaje y otros recursos semióticos: las escuelas, las iglesias, los medios y la industria del tiempo libre en general, pero también la familia, los sindicatos, los partidos políticos. La clase dominante impone su lengua y solo en épocas de gran conmoción, es cuando pueden imponerse visiones, valores y signos diferentes al en sí y para sí revolucionario. El antagonismo ideológico ha sido construido en la práctica de resistencia de grupos subalternos, comprendido como sujeto de la acción y de la transformación.

4. Posibilidad de la crítica hacia la deconstrucción del Lenguaje y el Deseo

El segundo trazo en el mapa, entre tantos otros, se articula a las relaciones de producción (Kristeva, 1981, 1999, 2015; Derrida, 1978, 
2012, 2014, 2017). Nos permite aproximarnos a una práctica-teórica de la significación, que toma como punto de partida los fundamentos básicos de la teoría estructuralista, que hacen posible la descripción sistemática de la coacción social y simbólica dentro de cada práctica discursiva y significante, como las prácticas de intervención social que dan cuenta de la radicación tanto social como corporal del lenguaje. Es así como podemos aproximarnos a las opresiones, las subalternidades y los antagonismos.

Si lo que caracterizaba a la posición estructuralista era la primacía del signo/sistema, esta propuesta supone la subversión a esta primacía, propone una ciencia crítica y desconstructiva que, a partir del texto, de la palabra, explora la lengua y cómo se configura la producción, la transgresión y la transformación de la significación.

Esta propuesta no supone una simple extensión del modelo lingüístico estructural a todo objeto considerado dotado de sentido, más bien se trata de una nueva concepción del lenguaje, que incorpora la noción de praxis en tanto que producción y puesta en crisis del sentido y del espacio social y subjetivo que los sujetos trazan en las estructuras, en los aparatos, se puede establecer una práctica-teórica del lenguaje como productividad, como posibilidades de transformación radical.

Kristeva (1999) nos plantea la idea que todo conjunto social se constituye también por la negativa, es decir, a partir de la producción y de la experiencia de alteridades radicales. La condición de posibilidad de los sujetos individuales y colectivos es la subversión o resistencia al orden establecido que radica en la institucionalidad y en la vigencia de fronteras simbólicas que se establecen en las relaciones de poder, cuya especificidad reside en designar el límite de lo social, en producir simultáneamente un ámbito de subjetividades jerarquizado, un espacio social construido, con sus tensiones o contrarios.

La labor es aportar a descentrar al sujeto parlante a través de su vinculación con lo que este ha excluido para constituirse. Específicamente, el sujeto descentrado, es el sujeto tal como aparece en el estructuralismo. A este sujeto sujetado (descentrado) por el orden simbólico, Kristeva (1999) en ese proceso reintegra los procesos pulsionales, semióticos y maternales del cuerpo. 
Entonces, des-centrar el sujeto supone pensar la función de la ideología dominante que esas exclusiones instalan en el ideario del sujeto libre, blanco y masculino, con efecto transcultural, transhistórico y transpolítico.

Como lo plantea Gayatri Spivak (2003), implica un ejercicio profundo esa:

(...) crítica de la constitución ideológica del sujeto dentro de las formaciones estatales y los sistemas de economía política puede borrarse ahora, de la misma manera que la práctica teórica activa de la 'transformación de la conciencia'. Queda revelada entonces la banalidad de las listas producidas por intelectuales de izquierda nombrando subalternos políticamente astutos que se conocen a sí mismos; representándolos, los intelectuales se representan a sí mismos como transparentes (Spivak, 2003:308-309).

Entonces, ¿puede el sujeto subalterno hablar?, ¿o sólo encuentra intelectuales traductores? De ese modo, adonde había un sujeto cuyos procesos inconscientes solo podían reproducir el orden societal, emerge un sujeto que puede ser transgresor y productivo de nuevos sentidos: un sujeto de lo reprimido y su retorno.

Es ir tensionando la identidad y su exceso, como aquel que actualiza la estructura simbólica del orden social al mismo tiempo que la excede y, en ese proceso, se subvierte a sí mismo. Se trata de un sujeto parlante que se transforma en un sujeto en ese movimiento.

Esta ruptura constitutiva sería una condición de posibilidad que permite la apertura hacia la crisis y transformación del orden social deconstruyendo la idea de crisis como posibilidad .

Desde este campo sería la irrupción de lo abyecto/a, y que será transformador/a en tanto y en cuanto transgreda los límites que el orden material y simbólico que se le confiere y que en las prácticas de intervención las encontramos, por qué extrañarnos al encontrar ese abyecto/a que tensiona procesos donde se les exige pautas de crianza, competencias parentales, condicionantes comportamentales, en las diferentes políticas sociales, etcétera. Por eso también la revuelta ha sido 
y seguirá siendo íntima, pero a la vez subversiva del orden simbólico, dándose de manera conjunta, retroalimentándose paso a paso.

Es encontrar un discurso más cercano a lo innombrable y lo abyecto, esto es, no será sino a través del acceso a la dimensión del lenguaje y de la práctica de la significancia, que podrán producir las crisis y los cambios, los acontecimientos que disloquen el orden.

\section{Algunos trazos para el cierre}

Las diferentes perspectivas o prácticas referenciadas como críticas operan sobre un objeto específico que es también un pretexto para abordar otras problemáticas, más generales, estructurales y estructurantes.

Debemos reconocer que las prácticas críticas pueden profundizar en dimensiones y categorías que cada una conlleva, pero también cocrear categorías desde lo dialógico, lo situado y las trayectorias de los pueblos.

Por ello, debemos tomar en cuenta dicha dimensión subjetiva, identificar la dirección que imprime en la elaboración de un concepto, los ingredientes que acentúa o al contrario desecha, ayuda a desenmarañar situaciones a primera vista absurdas y argumentaciones aparentemente irracionales, como las resistencias del sujeto social-deseante en dispositivos de intervención social, o frente al aparato ideológico denominado Trabajo Social.

El pensamiento crítico no puede limitarse a meros enunciados, su vigencia pasa hoy día por su capacidad performativa, su potencia comprensiva y explicativa, su abandono de toda satanización de la eficacia, de la eficiencia, de los protocolos y otros formalismos que importa principalmente deconstruir y secundariamente denunciar-transformar.

La crítica no significa el 'rechazo' de la realidad o de las perspectivas diferentes; por el contrario, la crítica no debe negar la realidad existente. Todo lo contrario, una perspectiva crítica radical tiene que partir de la realidad concreta de nuestros territorios y confrontar los signos, los conceptos con la propia realidad. Así, la crítica radical hoy se enfrenta al neoliberalismo y su proyecto no significa la fundación idealizada del "deber ser", ajena e independiente de cada formación 
económico-social, por lo que nos pone en pugna con y en el mismo neoliberalismo, con las paradojas y contradicciones que implica.

En la actualidad están dadas y se construyen las condiciones para el diálogo entre el pensamiento disciplinario (redefinido) y otras formas de saber emergentes (o resurgentes), diríamos en clave Saúl Karsz: prácticas transdisciplinarias. En cierto sentido, pareciera ser que se da cierta democratización en el ámbito del signo, una democratización radical.

Debemos asumir las paradojas o contradicciones, pueden crear las condiciones para rearticular la epistemología moderna y parcializarla en el encuentro con el conocimiento local.

Tratando de "interpretar" como herederos en algún sentido esta "paradoja", aparece como imprescindible tener en mente uno de los ejes de la reflexión: historizar el (los) lugares de enunciación del signo, para indagar las posibles implicaciones ideológico-materiales de este diálogo.

Cuando digo no olvidar a los maestros... es ser herederos/as de ellos, es un eterno retorno como ley del devenir.

Con Marx, en el sentido en que asumió el compromiso radical de la crítica; no se conformó con hacer crítica de una esfera particular de la existencia, sino que aspiró a "la crítica implacable de todo lo existente" (Marx, 1982:458).

Y con Nietzsche, quien nos interpela sobre los conceptos:

Toda palabra se convierte de manera inmediata en concepto en tanto que justamente no ha de servir para la experiencia singular y completamente individualizada a la que debe su origen (...) sino que debe encajar al mismo tiempo con innumerables experiencias, por así decirlo, más o menos similares, jamás idénticas estrictamente hablando; en suma, con casos puramente diferentes. Todo concepto se forma por equiparación de casos no iguales (Nietzsche, 1873:23).

Desde ellos, la crítica es una mirada sobre un dominio, sobre una pugna... como cartógrafo tuve que escoger, preferir, excluir, dejar caer, para responder al llamado de lo precedente, develando lo indecible del legado, adentrándonos en la herencia de la disciplina desde una 
deconstrucción contemporánea, revisitando y repensando el Trabajo Social para proyectar su por-venir latinoamericano.

\section{Referencias bibliográficas}

Badiou, Alain (2013). La filosofía y el acontecimiento; seguido de una Breve introducción a la filosofía de Alain Badiou. Buenos Aires, Argentina, Amorrortu.

Bambó-Naya, Raimundo; Sancho-Mir, Miguel y Ezquerra, Isabel (2019). El mapa y el territorio. Cartografías prospectivas para una enseñanza flexible y transversal. JIDA, 19, 117-132. DOI: https://doi.org/10.5821/jida.2019.8294

Cortés Mancilla, Rodrigo. (2017). Herencia, acontecimiento y cuerpos políticos en la intervención social: Una deconstrucción desde el trabajo social. Revista Intervención (7), 19-26.

Cortés Mancilla, Rodrigo (2020). Una práctica-teórica rizomática des/territorializada. Intervención en co-labor con el campamento Felipe Camiroaga. TS Cuadernos de Trabajo Social, 20, 78-101.

Dunayevskaya, Raya (2017). Rosa Luxemburgo, la liberación femenina y la filosofía marxista de la revolución. Recuperado de: http://rosalux.org.mx/sites/default/ files/node gallery/rosa luxemburgo por dunayevskaya.pdf

Deleuze, Gilles y Guattari, Félix (2020). Mil mesetas: Capitalismo y esquizofrenia. Valencia, España, Pre-textos

Derrida, Jacques (1978). De la Gramatología. Buenos Aires, Argentina, Siglo Veintiuno.

Derrida, Jacques (2012). Política y amistad: Entrevistas con Michael Sprinker sobre Marx y Althusser. Buenos Aires, Argentina, Nueva Visión.

Derrida, Jacques (2014). Posiciones: Entrevistas con Henri Ronse, Julia Kristeva, Jean-Louis Houdebine, Guy Scarpetta. Valencia, España, Pre-Textos.

Derrida, Jacques (2017). Psyché invenciones del otro. Buenos Aires, Argentina, La Cebra.

Derrida, Jacques y Roudinesco, Élisabeth (2009). Y mañana qué.... Buenos Aires, Argentina, Fondo de Cultura Económica.

González-Saibene, Alicia (2007). El objeto de intervención profesional: un mito del Trabajo Social. Revista UMBRAL Prácticas y Ciencias Sociales desde el Sur, 13, 3-43.

González-Saibene, Alicia (2015). Acerca de La Intervención. RUMBOS TS Un Espacio Crítico para la Reflexión en Ciencias Sociales, 11, 22-40.

González-Saibene, Alicia (2021). El impacto de las producciones filosóficas y teórico/epistemológicas en la constitución de la disciplina. Propuestas Críticas en Trabajo Social - Critical Proposals in Social Work, 1(1), 100. DOI: https://doi. org/10.5354/2735-6620.2021.61238

Lukács, Georg (2009). Historia y conciencia de clase: Estudios de dialéctica marxista. Buenos Aires, Argentina, Ediciones RyR.

Marx, Karl (2014). Introducción a la crítica de la filosofía del derecho de Hegel. Valencia, España, Pre-textos. 
Marx, Karl y Engels, Friedrich (2015). El manifiesto comunista. Madrid, España, Nórdica Libros.

Nietzsche, Friedrich (1998). Sobre verdad y mentira en sentido extramoral. Madrid, España, Tecnos.

Pérez de Lama, José (2009). La avispa y la orquídea hacen mapa en el seno de un rizoma: Cartografía y máquinas, releyendo a Deleuze y Guattari. Pro-Posições, 20(3), 121-145. DOI: https://doi.org/10.1590/S0103-73072009000300009

Perlongher, Néstor (1996). “Los devenires minoritarios”. En G. Goldchluk (Ed.) Prosa Plebeya. Ensayos 1980 - 1992. Buenos Aires, Argentina, Colihue.

Kristeva, Julia (1981). Sèmeiòtikè Semiótica. Madrid, España, Fundamentos.

Kristeva, Julia (1999). El porvenir de la revuelta. Buenos Aires, Argentina, Fondo de Cultura Económica.

Kristeva, Julia (2015). Poderes de la perversión: Ensayo sobre Louis-Ferdinand Céline. Buenos Aires, Argentina, Siglo Veintiuno.

Rancière, Jacques (1994). En los bordes de lo político (trad. Alejandro Madrid). Santiago de Chile, Chile, Universitaria.

Rey, Javier y Granese, Andrés (2019). La cartografía como método de investigación en psicología. Psicología, Conocimiento y Sociedad, 9(1). DOI: https://doi. org/10.26864/PCS.v9.n1.4

Rolnik, Suely (s. f.). Cartografía sentimental. Recuperado de: http://www.medicinayarte.com/libros-digitales/oficina/biblioteca/cartografia sentimental.htm

Spivak, Gayatri (2009). ¿Puede hablar el subalterno? Revista Colombiana de Antropología, 39, 297-364.

Voloshinov, Valentín (1999). Freudismo: Un bosquejo crítico. Buenos Aires, Argentina, Paidós.

Voloshinov, Valentín (2009). El Marxismo y la Filosofía del Lenguaje. Buenos Aires, Argentina, Godot.

Žižek, Slavoj (2018). Acontecimiento. México, Sexto Piso.

Recibido: 06/07/2021

Aceptado: 09/10/2021 